\title{
Fen Bilgisi Öğretmen Adaylarının Sorgulama Becerileri ve Bilimsel Süreç Becerilerinin EEG Ölçümleri ile İlişkilendirilmesi1
}

\section{Association of Pre-Service Science Teachers' Inquiry and Scientific Process Skills with EEG Measurement}

\author{
Burçin ACAR ŞEŞEN ${ }^{2}$, Ayfer MUTLU ${ }^{3}$, Seda USTA GEZER ${ }^{4}$, Elif iNCE ${ }^{5}$
}

\section{Öz}

Sunulan çalışmada, sorgulamaya dayalı öğrenme ortamında ve geleneksel öğrenme ortamında öğrenim görmüş olan fen bilgisi öğretmen adaylarının sorgulama becerilerinin ve bilimsel süreç becerilerinin EEG ölçümleri ile ilişkilendirilmesi amaçlanmıştır. Araştırma, Fen Bilgisi Öğretmenliği lisans programına kayıtlı birinci sınıf öğretmen adayları ile yürütülmüştür. Araştırma sürecinde, deney grubunda $(\mathrm{N}=10)$ yer alan öğretmen adayları Genel Kimya Laboratuvarı-II dersi kapsamında bir dönem süresince sanal laboratuvar ortamında sorgulamaya dayalı deneysel etkinlikler, kontrol grubundaki ( $N=10)$ öğretmen adayları ise yine sanal laboratuvar ortamında geleneksel yaklaşıma dayalı deneysel etkinlikleri gerçekleştirmiştir. Her iki gruptaki öğrencilere uygulamaların sonrasında problem durumu verilmiş ve hipotez kurmaları istenmiştir. Öğrencilerin dinlenme ve problem durumuna dayalı olarak hipotez kurma aşamalarında EEG kaydı alınmıştır. Araştırma kapsamında, EEG verileriyle ilişkilendirme amacıyla veri toplama araçları olarak uygulamalardan sonra Sorgulama Becerileri Ölçeği ve Bilimsel Süreç Becerileri Testi uygulanarak değerlendirilmiş ve yarı yapılandırılmış görüşmeler yapılmıştır. Analiz sonuçlarına göre deney ve kontrol gruplarının bilimsel süreç becerileri $(U=9.500, z=-3.077, p<0.05, r=0.69)$ ve sorgulama becerileri $(U=15.000, z=-2.655, p<0.05$, $r=0.59$ ) ortalama puanları arasında deney grubu lehine anlamlı bir farklılık olduğu saptanmıştır. Deney ve kontrol grubundaki katılımcıların hipotez geliştirirken sağlanan frontal teta frekansı gücü kıyasladığında ise her gruptaki katılımcıların frontal teta frekansı gücünün değişiminin benzer olduğu ve iki grup arasında fark olmadığı belirlenmiştir. Bu durum, her iki grubun kullanılan öğrenme yaklaşımına bağı olmaksızın hipotez kurma sürecinde beyninin belli bir bölgesinin aktif olduğu ve benzer refleksi verdiğini ancak sorgulamaya dayalı ortamda çalışan öğrencilerin bilimsel süreç ve sorgulama becerilerinin daha yüksek olduğunu göstermektedir.

\section{Anahtar Kelimeler: bilimsel süreç becerileri, EEG, sorgulama becerileri, sorgulamaya dayalı öğrenme}

\section{Abstract}

In the present study, it is aimed to associate inquiry skills and scientific process skills of pre-service science teachers, who have been educated in inquiry-based learning environment and traditional learning environment, with EEG measurements. This study was carried out by the participation of first grade pre-service teachers in Science Education undergraduate program. Preservice science teachers in the experimental group $(\mathrm{N}=10)$ performed inquiry-based laboratory work and the pre-service science teachers in the control group $(\mathrm{N}=10)$ conducted traditional recipe-like laboratory work in virtual laboratory environment in the context of General Chemistry Laboratory - II course during a semester. After the laboratory works, a problem situation was given and the pre-service science teachers in both groups were required to formulate hypothesis. EEG records of all the participants in both groups were taken in resting time and step of defining hypothesis. Inquiry Skills Scale and Scientific Process Skills Tests were applied after the instruction as data collection tools to associate with EEG data. Semi structured interviews were also performed. According to results, there were significant differences between experimental and control groups' both scientific process skills test $(U=9.500, z=-3.077, p<0.05, r=0.69)$ and inquiry skills $(U=15.000, z=-2.655, p<0.05, r=0.59)$ in favour of experimental group. There was no difference between experimental and control groups' power of fronthal theta frequency in step of defining hypothesis. Based on findings, it is interpreted that pre-service science teachers' brain has similar reflex regardless of the learning approach but inquiry and scientific process skills of the pre-service science teacher in the experimental group is higher than control group.

Keywords: EEG, inquiry-based learning, inquiry skills, scientific process skills

\footnotetext{
${ }^{1}$ Bu çalışma İstanbul Üniversitesi-Cerrahpaşa Bilimsel Araştırma Projeleri Koordinasyon Birimi tarafından desteklenmiştir. Proje numarası: 50694

2 İstanbul Üniversitesi-Cerrahpaşa, Hasan Ali Yücel Eğitim Fakültesi Matematik ve Fen Bilimleri Eğtimi Bölümü, İstanbul, Türkiye

${ }^{3}$ Kırklareli Üniversitesi Sağlık Hizmetleri Meslek Yüksekokulu, Kırklareli, Türkiye

${ }^{4}$ İstanbul Üniversitesi-Cerrahpaşa, Hasan Ali Yücel Eğitim Fakültesi Matematik ve Fen Bilimleri Eğtimi Bölümü, İstanbul, Türkiye

5 İstanbul Üniversitesi-Cerrahpaşa, Hasan Ali Yücel Eğitim Fakültesi Matematik ve Fen Bilimleri Eğtimi Bölümü, İstanbul, Türkiye 


\section{Extended Abstract}

Introduction: Science education aims to train students who investigate, gain knowledge and use it in their life, have communication skills etc. For this reason, active learning approaches have major importance in science education. Inquiry based learning is one of these active learning approaches. Inquiry-based learning is a scientific activity that provides students to learn scientists' works and scientific thinking. In this approach, students define problem, formulate hypothesis for solution the problem, plan an investigation to prove their hypothesis, collect data, interpret their results and share them with their classmates. They conduct scientific investigation using scientific method by this way. It was found that inquiry-based learning was effective to promote students' inquiry and scientific process skills in studies in the literature.

In the learning environment, there are many stimulus and they are cause several reflex in the learners' brain. Electroencephalography is a neurophysiologic method that used for analyzing of changes in the brain. Recording of the electrical potential of the brain using electrodes is also called electroencephalogram. In the EEG, the electrode names are expressed in letters and numbers. Letters indicate the brain lobes as Fp: frontoparietal, F: frontal, C: central, T: temporal, P: parietal, O: occipital. While the left side and the right side of electrodes are indicated single and double numbers, respectively and $z$ indicated in the middle line. The EEG has 4 frequency bands, delta, theta, alpha and beta waves. Records in the EEG showed that information about the diseases occurring in the brain, the causes of the disease and the events occurring in the metabolism. In education, it is generally used in the diagnosis of attention deficit and learning disorders. EEG spectral power analysis is performed, the upper band of the spectral power of the alpha band is carefully and the sub-band is associated with mental effort. If frequency of EEG waves increases and waves' amplitude decreases, level of brain activity increases. EEG can be used in education owing to this attribute.

In the present study, it is aimed to associate inquiry skills and scientific process skills of pre-service science teachers, who have been educated in inquiry-based learning environment and traditional learning environment, with EEG measurements.

Method: The present study was conducted by participation of 20 pre-service science teachers who were divided into experimental and control groups. Eight laboratory activities related to chemical kinetics, thermochemistry, chemical equilibrium, acids-bases and electrochemistry were developed and conducted in virtual laboratory environment. While these activities were based on inquiry-based learning in the experimental group, they were based on traditional recipe-like learning. Inquiry-based virtual laboratory activities had steps of inquiry based laboratory such as defining of problem, to formulate of hypothesis, to design and conduct an experiment, data collection, to interpret and share results. Traditional recipe-like virtual activities were accomplished following laboratory guide presented in the software step by step. Scientific Process Skills Test and Inquiry Skills Scale were used and semi structured interview was performed. Then, problem situation was presented all participants and they were required to define a hypothesis for solution of the problem. EEG records of all the participants in both groups were also taken in resting time and step of defining hypothesis. Mann Whitney $U$ test was performed to assess data obtained from Scientific Process Skills Test and Inquiry Skills Scale. Brainvision EEG Analyzer was used to evaluate of EEG records. Semi structured interviews were analyzed using content analysis.

Findings: According to Mann Whitney-U test results, there were significant differences between experimental and control groups' both scientific process skills test $(U=9.500, z=-3.077, p<0.05, r=0.69)$ and inquiry skills $(U=15.000$, $z=-2.655, p<0.05, r=0.59$ ) in favour of experimental group. It was identified 26 codes and four themes in the context of context analysis. Based on interview results, major of the pre-service science teachers in the experimental group expressed clearly that their skills especially defining hypothesis improved, activities provided deeply thinking, more inquiring, more improving owing to feedback. However, there was also no difference between experimental and control groups' power of fronthal theta frequency in step of defining hypothesis.

Results and Suggestions: Based on findings, similar reflex occurred in the pre-service science teachers' brain regardless of the learning approach. However, score obtained from inquiry skills scale of experimental group is 
statistically significantly higher than control group. Similarly, experimental group's scientific process skills test score is higher than control group's score. This situation can be interpreted that inquiry-based learning environment provided to use these skills. If inquiry-based learning is used in control group instead of traditional recipe-like approach, the pre-service science teachers in the control group may have higher score. For this reason, learning environments in teacher training programs should be supported active learning approach for the pre-service science teachers' effective lessons in their future classroom. 


\section{Giriş}

Günümüzde yaşanan bilimsel ve teknolojik gelişmeler ışı̆̆ında fen eğitiminin öncelikli amaçları yeniden şekillenmiştir. Günümüz fen bilimleri bilgiyi üreten, günlük hayatta kullanan, eleştirel düşünen, problem çözen, girişimci olma, iletişim kurma ve kararlılık becerilerine sahip, toplumuna ve kültürüne katkı sağlayan bireylerin yetiştirilmesi amaçlamaktadır (Milli Eğitim Bakanlığı, 2018). Öğrencilerin bu vasıflara sahip olarak yetiştirilmesinde öğrenme ortamlarının önemi büyüktür. Eğitim sistemimizde yoğun olarak tercih edilen geleneksel öğretmen merkezli yaklaşımın yeterlilikleri son yıllarda yapılan araştırmalarla sorgulanmış ve eğitim araştırmacıları nitelikli öğrenci yetiştirmede aktif öğrenme yaklaşımlarının fen programlarında uygulanmasına yoğunlaşmışlardır. Fen öğretim programlarının 2018 yılında sorgulamaya dayalı yaklaşımı temel alır şekilde düzenlenmesi bu alanda atılan önemli adımlardan biridir.

Sorgulamaya dayalı öğrenme ölçme, gözlem yapma, tahminde bulunma, çıkarımlarda bulunma, hipotez oluşturma, veri toplama, değişkenleri belirleme ve kontrol etme, iletişim gibi becerileri içeren, öğrencilerin bilimsel düşünmeyi ve bilim insanlarının nasıl çalıştıklarını öğrendikleri bilimsel etkinliklerdir (NRC, 2000). Sorgulamaya dayalı öğrenmenin öğrenme ortamlarında uygulanması ile öğrencilerin bilgi kazanması, temel kuram ve ilkeleri anlaması, temel ve soru sorma becerilerinin gelişmesi, olumlu tutum geliştirmesi sağlanır (Chiappetta ve Adams, 2004).

Sorgulamaya dayalı öğrenme, öğretmen ve öğrenci rollerine göre farklı düzeylere sahiptir. Sorgulamaya dayalı öğrenmenin düzeyleri Schwab (1962) tarafından üç düzey olarak tanımlanmış, daha sonra yapılan çeşitli çalışmalarla bu düzeyler revize edilmiş ve yeni düzeyler eklenmiştir. En öğretmen merkezli düzey olan doğrulayıcı sorgulamada öğretmen tarafından elde edilecek sonuçlar da dahil sürece ait tüm bilgiler verilir ve öğrenciler bu bilgileri doğrularlar. Yapılandırılmış sorgulamada ise sürece ait yönerge öğretmen tarafından sunulurken öğrenciler bu yönergeyi izleyerek sonuçlara ulaşır. Rehberli sorgulamada problem öğretmen tarafından verilirken, problemi çözmek için izlenecek yol ve problemin çözümü öğretmen rehberliğinde öğrenci tarafından belirlenir. En öğrenci merkezli düzey olan açık sorgulamada ise öğrenciler tüm aşamaların yöneticisidir. Öğrenciler çalışacakları konuyu, çözümlemek istedikleri problemi, problemin çözümü için kullanacakları yöntemi ve sonuçları kendileri belirlerler.

Alan yazında sorgulamaya dayalı öğrenmenin çeşitli değişkenlere etkisinin incelendiği çalışmalara eğitimin her kademesinde rastlanmaktadır. Sorgulamaya dayalı öğrenmenin bilimsel süreç becerileri ve sorgulama becerilerine etkisine ilişkin ulusal ve uluslararası çalışmalar incelendiğinde, Wu ve Hsieh (2006) sorgulamaya dayalı öğrenme ortamlarında 6. Sınıf öğrencilerinin sorgulama becerilerinin gelişimini incelemiş, video kaydı, öğrenme etkinlikleri, görüşmeler, ön test son test uygulamaları gibi çoklu veri kaynağı kullanmışlardır. Çalışmanın sonuçları sorgulamaya dayalı etkinliklerin öğrencilerinin sorgulama becerilerini geliştirdiğini göstermiştir. Ergül vd. (2011)'nin 4., 5., 6., 7. ve 8. sınıfa devam eden $121^{\prime} \mathrm{i}$ deney, 120'si kontrol olmak üzere 241 öğrencinin katılımıyla gerçekleştirdikleri çalışmalarında, deney grubu sorgulamaya dayalı deneyler yaparken, kontrol grubu geleneksel yaklaşımla eğitim almıştır. Bilimsel süreç becerileri testinden elde sonuçlara göre sorgulamaya dayalı deneyler yapan öğrencilerin bilimsel süreç becerileri anlamlı düzeyde gelişmiş̧ir. Khan ve Iqbal (2011)'in deney ve kontrol grubuna ayırdığı 9. sınıf öğrencileri ile yürüttüğü çalışmalarında, deney grubunda bazı biyoloji konularında sorgulamaya dayalı laboratuvar uygulamaları yapılırken, kontrol grubunda geleneksel yaklaşım temel alınmıştır. Ön ve son test olarak uygulanan bilimsel süreç becerileri ölçeğinden elde edilen bulgulara göre bilimsel süreç becerilerini geliştirmede sorgulamaya dayalı laboratuvar uygulamaları daha etkili olmuştur. Kaya ve Yılmaz (2016) açık sorgulamaya dayalı öğrenmenin bilimsel süreç becerilerinin gelişimine etkisini araştırmıştır. 55 öğrencinin katılımıyla gerçekleşen çalışmada ders deney grubunda açık sorgulamaya dayalı öğrenme etkinlikleri, kontrol grubunda ise öğretim programı temel alınarak yürütülmüştür. Çalışmanın sonuçları sorgulamaya dayalı öğrenmenin bilimsel süreç becerilerini geliştirdiğini göstermiş̧ir. Hairida (2016) sorgulamaya dayalı modülün sorgulama becerilerine etkisini araştırdığı çalışmasında 7. sınıf öğrencilerini deney ve kontrol olmak üzere iki gruba ayırmış, deney grubunda sorgulamaya dayalı modülü kontrol grubunda ise geleneksel yaklaşımı uygulamıştır. Sorgulama beceriler gözlem kağıtlarından elde edilen sonuçlara göre sorgulamaya dayalı öğrenmenin geleneksel yaklaşıma kıyasla sorgulama becerilerini geliştirmede daha etkili olduğunu bulunmuştur. Şensoy ve Yıldııım (2017), 92 fen öğretmen adayının katılımıyla yürüttüğü çalışmasında deney grubunda 
sorgulamaya dayalı programı uygularken kontrol grubunda geleneksel yaklaşımı temel almıştır. Araştırma sonuçları deney grubunun bilimsel süreç becerilerinin kontrol grubuna kıyasla daha fazla arttığını göstermektedir. Benzer şekilde sınıf öğretmen adayları ile yürüttükleri çalışmalarında Yıldırım, Kurt ve Güneş (2014) ve dördüncü sınıf öğrencileri ile yürüttüğü çalışmasında Yıldırım ve Türker-Altan (2017) sorgulamaya dayalı öğrenmenin bilimsel süreç becerilerini geliştirmede geleneksel yaklaşıma kıyasla daha etkili olduğunu bulmuştur.

Öğrenme ortamlarında çeşitli uyaranlar bulunmaktadır ve bu uyaranlar beyinde çeşitli reflekslere yol açmaktadır. Öğrenme ortamında çeşitli uyaranlar yaratıldığında beyinde meydana gelen değişimleri analiz etmeye yönelik nörofizyolojik yöntemlerden biri de elektroensefalografidir. Çeşitli yazdırma ve yükseltme sistemleri yardımıyla işlenerek beynin biyoelektrik aktivitesinin incelenmesi elektroensefalografi (EEG), beynin elektrik potansiyelinin elektrotlar vasıtasıyla kafatası üzerinden kaydedilmesine ise elektroensefalogram denir. EEG'de elektrot isimler harfler ve rakamlarla ifade edilir. Harfler Fp: frontoparietal, F: frontal, C: central, T: temporal, P: pariyetal, O: oksipital şeklinde beyin loblarını gösterirken, sol taraftaki elektrotlar tek, sağ taraftakiler çift sayılar, orta hat ise $z$ ile gösterilir. EEG'de delta, teta, alfa ve beta dalgaları olmak üzere 4 frekans bandı bulunmaktadır. EEG dalgalarının frekansının yükselmesi ve genliklerinin azalması beynin aktivite düzeyinin artışına işarettir (Pehlivan, 1997).

EEG kaydında sinyal üzerindeki değişiklikler yardımıyla beyinde meydana gelen hastalıklar, hastalığın sebepleri ve metabolizmada gerçekleşen olaylar hakkında bilgi sahibi olunabilmektedir. Eğitim alanında ise genel olarak dikkat eksikliği ve öğrenme bozukluklarının teşhisinde kullanılmaktadır. Bu amaçla EEG spektral güç analizi yapılmakta, alfa bandının spektral gücüne ait üst bant dikkatle, alt bant ise mental eforla ilişkilendirilmektedir (Jausovec ve Jausovec, 2000). Bir diğer spektral güç analizinde ise teta dalgası ölçülmekte ve frontal teta dalgalarının değişimi öğrenme ile ilişkilendirilmektedir (Summerfield ve Magels, 2004). EEG'de ayrıca farklı beyin bölgelerinin senkronize hareketlerinin derecesinin belirlendiği koherans analizi kullanılmakta, koheransın etkin öğrenme durumunda arttığı bilinmektedir (Mölle vd., 2004).

Uluslararası alan yazında öğrenme ortamı, yaratıcılık, öğrenme stilleri, problem çözme gibi alanlarda EEG ölçümlerinin analizine yönelik çalışmalar mevcut olup sorgulamaya dayalı öğrenme ortamında gerçekleştirilen ve bireylerin sorgulama becerileri, bilimsel süreç becerilerinin ile EEG kayıtlarının ilişkilendirildiği ulusal ve uluslararası düzeyde çalışma bulunmamaktadır. Örneğin, Jausovec (2000), EEG kayıtları yardımıyla üstün, yaratıcı, zeki ve orta düzeydeki bireyleri farklı komplekslikteki problemleri çözerken kıyaslamıştır. Psikoloji dersini alan sağlak 49 öğretmen adayının katılımıyla gerçekleştirilen çalışmada, farklı gruplara ayrılan adaylara çeşitli testler uygulanmış, bilgisayar ortamında doğru cevaba ne kadar sürede ulaştıkları ve amaca ulaşabilmek için izlenen basamak sayısı analiz edilmiştir. EEG kayıtları, yüksek zekâ düzeyine sahip çocukların, normal zekâ düzeyine sahip çocuklara göre problem çözerken daha az zihinsel aktivitede bulunduklarını (daha yüksek alfa) ve farklı beyin alanlarının daha koordineli çalıştığını (yüksek koherans) bulgulamaktadır. Jin vd. (2006), hipotez geliştirme sürecinde bilgi miktarındaki değişimi incelemek amacıyla 32 kanallı EEG sistemini kullanarak 16 elektrot takılmış başlıklarla kayıtlar almıştır. Hipotez geliştirme sürecinde öğrencilere 20 bıldırcın yumurtası gösterilmiş ve bazı sorular yönlendirilerek yumurtaları incelemeleri istenmiştir. Öğrenciler, yumurtaların farklı özelliklerinde olmalarına yönelik hipotez geliştirirken EEG kayıtları alınmıştır. Sonuçlar, hipotez geliştirme sürecinde beyin aktivitelerinin, beynin farklı bölgeleriyle ilişkili olduğunu göstermiştir. Hipotez geliştirme sürecinde, bilgi transfer miktarının temporal, parietal ve okkipital korteks bölgelerinin büyük bir kısmında arttığı saptanmıştır. Stevens, Galloway ve Berka (2006), wireless başlıklar kullanarak çalışan hafıza, dikkat dağınıklı̆̆ı, odaklanma ve problem çözme yeterliliği arasındaki ilişkileri ve ayrıca bir dizi nitel özellikteki kimya, biyoloji ve matematik simülasyonlarının etkilerini belirlemeyi amaçlamışlardır. EEG sonuçları, süreç boyunca deneyim kazanan öğrencilerin problemin özgünlüğü azaldıkça odaklanma düzeyinin düştüğünü, çalışan hafızanın aynen kaldığını, dikkat dağınıklığının değişkenlik gösterdiğini ortaya koymuştur. EEG-dikkat dağınıklığının problemin zorluk derecesi, verileri ilişkilendirememe ve/veya problem çözümünde belirsizlik yaşama ile ilişkili olduğu belirtilmiştir. Fink vd. (2009), nörofizyolojik ölçüm yöntemlerinden EEG ve fMRI kullanarak yaratıcı düşünme süresince beyin aktivitelerini ölçmüşlerdir. Her iki ölçüm esnasında öğrenciler yaratıcı fikir geliştirmeyle ilgili dört sözel işi yerine getirmişlerdir. Sonuçlara göre, EEG kayıtları, orjinal fikir geliştirmenin ön beyin bölgesindeki alfa senkronizasyonuyla ve parietal 
kortikal bölgedeki alfa senkronizasyonunun dağılması ile ilişkili olduğu saptanmıştır. fMRı sonuçları ise verilen işteki performansın sol hemisferin ön bölgesiyle yakından ilişkili olduğunu göstermiştir. Rashid vd. (2012), öğrenme stilleri ve hoşnutlukları arasındaki ilişkileri EEG kayıtları yaparak incelemiştir. Çalışmanın katılımcıları, Kolb Öğrenme Stilleri Envanteri kullanılarak 4 gruba ayrılmıştır. Beta band beyin dalgaları incelenerek öğrenme stilleri ve hoşnutluk arasında ilişkiler incelenmiştir. Sonuçlar, özümseyen öğrenme stili ile hoşnutluk arasında korelasyon olduğunu göstermiştir.

Öğretmen eğitimi gelecek nesillerin yetiştirilmesinde anahtar bir rol oynamaktadır. Çünkü öğrencinin niteliği doğrudan öğretmenin niteliğine bağlıdır. Her ne kadar eğitim sistemlerinde yeniliklere gidilse de bu yeniliklerin sınıf ortamında uygulanması öğretmenlere bağlıdır. Bu bağlamda öğretmen eğitiminde öğretmen adaylarının farklı öğrenme ortamlarında yer alması ve bu ortamlarda bilgi ve becerilerinin geliştirilmesi büyük önem arz etmektedir.

\section{Çalışmanın Amacı ve Problem Cümleleri}

Sunulan çalışmada, sorgulamaya ve geleneksel öğretmen merkezli yaklaşıma dayalı öğrenme ortamlarında öğrenim görmüş olan fen bilgisi öğretmen adaylarının sorgulama becerilerinin ve bilimsel süreç becerilerinin EEG ölçümleri ile ilişkilendirilmesi amaçlanmıştır. Bu doğruluda, çalışmanın problem cümleleri şu şekilde belirlenmiştir:

1. Sorgulamaya dayalı ve geleneksel öğretmen merkezli öğrenme ortamlarında öğrenim gören öğretmen adaylarının bilimsel süreç becerileri arasında anlamlı bir farklılık var mıdır?

2. Sorgulamaya dayalı ve geleneksel öğretmen merkezli öğrenme ortamlarında öğrenim gören öğretmen adaylarının sorgulama becerileri arasında anlamlı bir farklılık var mıdır?

3. Sorgulamaya dayalı ve geleneksel öğretmen merkezli öğrenme ortamlarında öğrenim gören öğretmen adaylarının bilimsel süreç becerileri, sorgulama becerileri ve EEG ölçümleri arasında nasıl bir ilişki vardır?

\section{Yöntem}

\section{Çalışma Grubu}

Sunulan çalışma, Fen Bilgisi Öğretmenliği lisans programı 1. sınıfında öğrenim görmekte olan sağlıklı ve sağ ellerini kullanan 20 öğretmen adayının (19-21 yaş aralığında) gönüllü katılımıyla gerçekleştirilmiştir. Uygulama öncesinde araştırma grubunu oluşturan Fen Bilgisi öğretmen adayları gerçekleştirilecek araştırmanın amaçları, veri toplama araçlarının uygulanışı, uygulanan veri toplama araçlarından elde edilecek kişisel bilgilerin ve verilerin gizliliği konusunda bilgilendirilmiş ve onayları alınmıştır. Öğretmen adayları rastgele yollarla deney $(N=10)$ ve kontrol grubuna $(\mathrm{N}=10)$ atanmıştır.

\section{Çalışmada Kullanılan Ölçme Araçları}

\section{Sorgulama Becerileri Ölçeği}

Araştırma kapsamında, EEG verileriyle ilişkilendirme amacıyla Aldan-Karademir ve Saracaloğlu (2013) tarafından geliştirilen 5'li Likert tipi Sorgulama Becerileri Ölçeği kullanılmıştır. Ölçeğin geliştirilme sürecinde alan yazın taraması yapılmış, farklı programlarda öğrenim gören 74 öğretmen adayının sorgulama ve sorgulama becerileri kavramlarına ilişkin düşüncelerini ele aldıkları kompozisyonlar değerlendirilmiş ve sorgulama kavramının temel boyutları çerçevesinde 55 maddeden oluşan deneme formu oluşturulmuştur. Form farklı anabilim dallarında yer alan 18 akademisyenin uzman görüşüne sunulmuş ve dönütler ışığında deneme formuna son hali verilmiştir. Deneme formu 425 öğretmen adayına uygulanmıştır. Açımlayıcı faktör analizi sonucunda, ölçeğin 14 maddeden ve "Bilgi Edinme”, "Bilgiyi Kontrol Etme" ve "Özgüven" olmak üzere üç faktörden oluşmasına karar verilmiştir. Cronbach-alpha güvenirlik katsayıları "Bilgi Edinme” için 0.76; "Bilgiyi Kontrol Etme” için 0.66 ve “Özgüven” için 0.82 iken, ölçeğin toplamı için ise 0.82' olarak hesaplanmıştır. Maddelerin puanlanması; Her zaman=5, Çoğunlukla=4, Ara sıra=3, Nadiren=2, Hiçbir zaman=1 şeklindedir.

\section{Bilimsel Süreç Becerileri Testi}

Çalışma kapsamında bilimsel süreç becerilerinin değerlendirilmesi amacıyla Burns, Okey ve Wise (1985) tarafından geliştirilen, Türkçe'ye uyarlama çalışmaları ise Ateş ve Bahar (2002) tarafından gerçekleştirilen Bilimsel 
Süreç Becerileri testi kullanılmıştır. Test 36 çoktan seçmeli maddeden, her test maddesi ise 4 seçenekten oluşmaktadır. Test maddeleri 5 beceriyi ölçecek şekilde geliştirilmiştir: Değişkenleri tanımlayabilme (12 madde), işlemsel açıklama getirebilme (6 madde), hipotez kurma ve tanımlama (9 madde), grafiği ve verileri yorumlama (6 madde) ve araştırma tasarlama (3 madde). Testin güvenilirlik katsayısı Burns, Okey ve Wise (1985) tarafından 0.86 olarak bulunmuştur. 203 kişi ile gerçekleştirilen uyarlama çalışmalarında ise test yarıları arasındaki korelasyon katsayısı 0.60, güvenilirlik katsayısı (Spearman-Brown) ise 0.74 olarak hesaplanmıştır.

\section{EEG Kayıtları}

Öğretmen adaylarının dinlenme ve hipotez durumu belirlemeleri sürecinde veri toplama amacıyla EEG kayıtları alınmış ve analiz edilmiştir. İyi bir EEG çekimi yapabilmek için kafa yüzeyi üzerinde direnç oluşturarak elektrotların performansının düşmemesi için öğretmen adaylarının yıkanmış ve kuru saçla gelmeleri istenmiştir. Bu şekilde gelemeyen kişilerin, özel bir odada saç yıkama ve kurulama işlemlerini yapmaları istenmiştir. Aynı zamanda verimli bir ölçüm için vücuttan veya dışarıdan kaynaklanan, gürültü veya istenmedik etkileri azaltacak önlemler alınmıştır. Bu nedenle öğretmen adayları dışarıdan gelecek seslere karşı izole edilmiş, ışık düzeyi istenilen düzeye göre ayarlanmış, rutubetsiz, normal oda sıcaklı̆ında olan EEG çekim odasına bireysel olarak alınmışlardır. Öğretmen adayları hareket sınırlamaları hakkında bilgilendirilmiş ve EEG çekim sürecinde konuşma, hareket etme gibi aktivitelerde bulunmamaları yalnızca düşünmeleri konusunda uyarılmışlardır.

EEG kayıtlarının elde edilmesi sürecinde, EEG kayıtları uluslararası 10-20 sistemine göre hazırlanmış bir başlıkla başa oturtulan 64 aktif elektrot yardımıyla $500 \mathrm{~Hz}$ örnekleme sıklığında alınmıştır. Elektrotlar her iki kulak elektrotlarının ortalamasına refere edilmiştir ve toprak elektrodu alına yerleştirilmiştir. Bütün elektrotlar için kayıt sırasındaki empedans değeri 5 ohm altında tutulmuştur. EEG ölçümü alınacak bir öğretmen adayı Şekil-1'de görülmektedir.

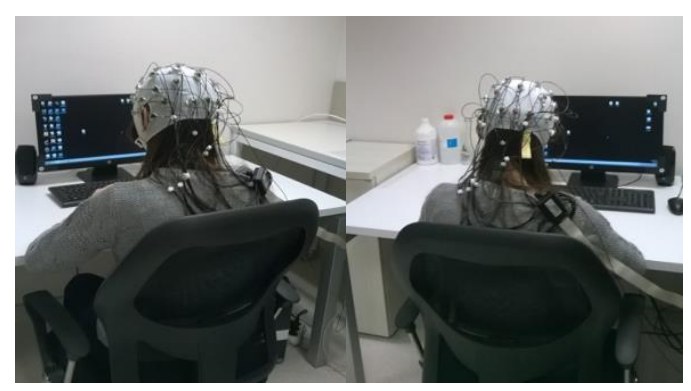

Şekil 1: EEG kayıtları için hazırlanan öğretmen adayı

EEG ölçümü için öğretmen adayı hazır hale getirildikten sonra ilk olarak üç dakika boyunca bilgisayar ekranına bakarak dinlenmeleri istenmiştir. Bu aşama için öğretmen adaylarına bilgisayar ekranında yönerge sunulmuştur (Şekil 2). 


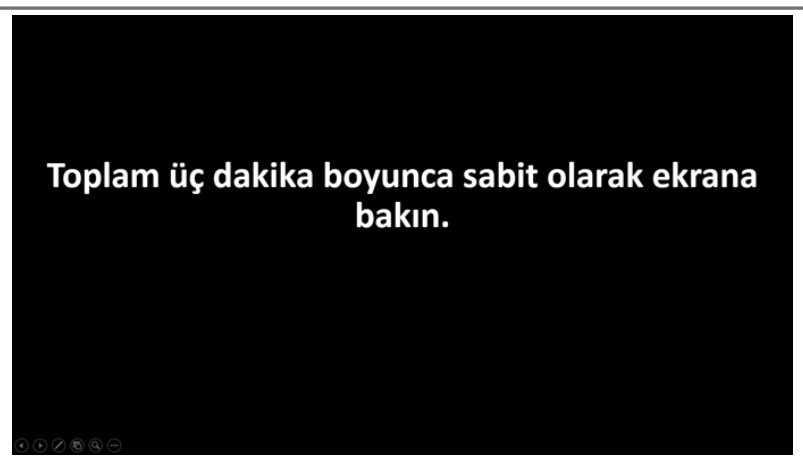

Şekil 2 : Dinlenme aşamasına ait yönerge

Dinlenme aşaması sonrasında öğretmen adaylarının verilen problem durumuna yönelik hipotez oluşturma aşamasına geçilmiştir. Bu aşamada öncelikle, öğretmen adaylarını sürece hazırlamak için Şekil 3'te sunulan ekran gösterilmiştir. Bu süreçte konuşmamaları ve sadece düşünmeleri istenmiştir.

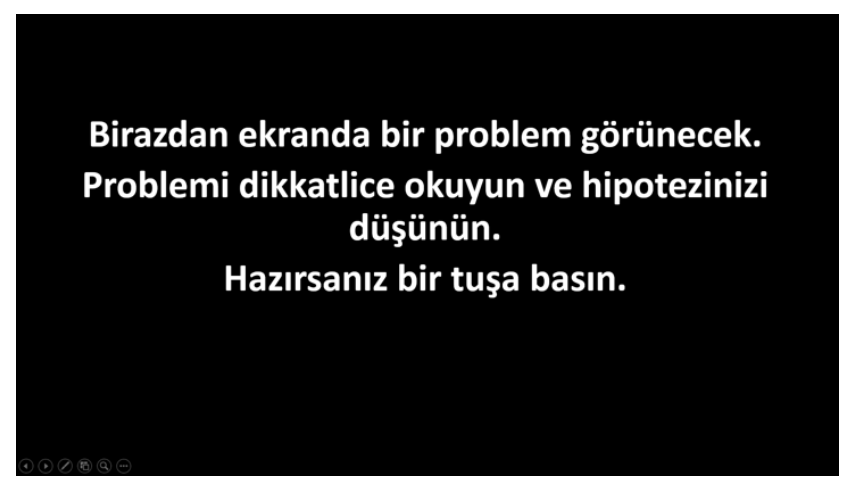

Şekil 3: Senaryoların sunulmasının ardından ekranda görülen yönerge

Bilgisayar ekranında bir senaryo sunulmuştur (Şekil 4). Ardından senaryolardaki problem durumuna dayalı olarak hipotez kurmaları istenmiştir (Şekil 5).

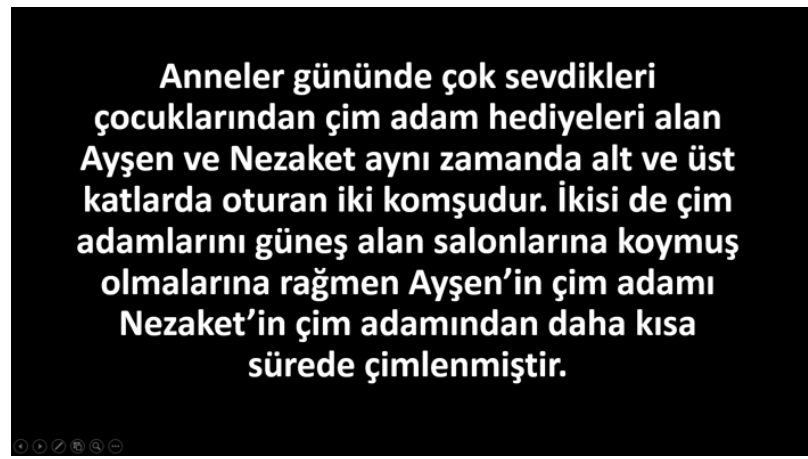

Şekil 4: Sunulan senaryo

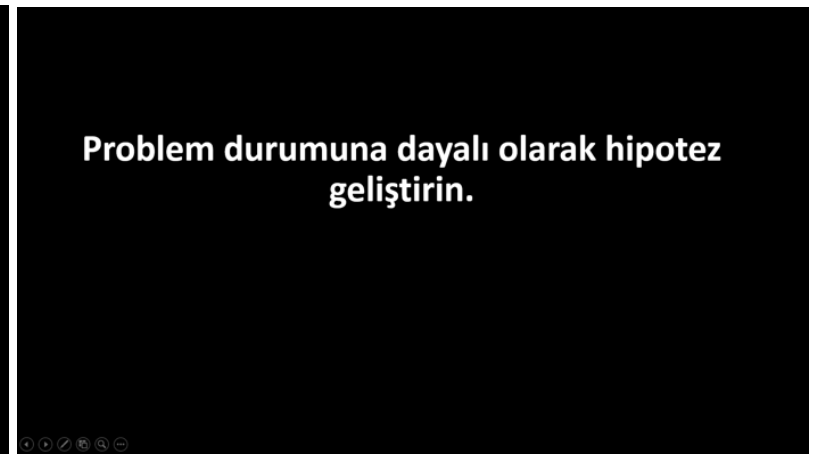

Şekil 5: Hipotez geliştirme süreci

\section{Görüşme Soruları}

Öğretmen adaylarının uygulama sürecine yönelik görüşlerinin daha ayrıntılı bir şekilde analiz edilmesi amacıyla yarı yapılandırılmış görüşme yapılmıştır. Görüşme soruları araştırmacılar tarafından hazırlanmış açık-uçlu sorulardan oluşmaktadır. Sorular öğretmen adaylarının, sürece yönelik düşüncelerini birebir tespit etmeyi amaçlamakla birlikte, bu düşüncelerin nedenlerine ilişkin görüşleri sorgulamayı da hedeflemektedir. Görüşme sürecinde yöneltilen sorulardan birkaçı aşağıda örneklenmektedir.

- Bu uygulamada hoşuna giden bir bölüm var mıydı? Kendi deneyini oluşturman konusunda ne düşünüyorsun? 
- Bu uygulamada güçlük çektiğin bir bölüm var mıydı? Deneyde, I. Problem oluşturma, II. Hipotez cümlesini oluşturma, IV. Deneyi tasarlama, V. Deneyi uygulama ve VI. Deney sonuçlarını yorumlama aşamalarından hangisinde güçlük çektin? Neden?

\section{İşlem}

Gerçekleştirilen çalışma kapsamında, öğretmen adayları rastgele yollarla deney ve kontrol grubuna atanmıştır. Gruplarda uygulanmak üzere Mutlu (2015) tarafından geliştirilen 8 deneysel etkinlik kullanılmıştır (Tablo 1).

\section{Tablo 1. Gruplarda Gerçekleştirilen Deneysel Etkinlikler}

\begin{tabular}{ll}
\hline Konu & Etkinliğin Amacı \\
\hline Kimyasal kinetik & Temas yüzeyi, sıcaklık, karıştırma ve madde miktarının tepkime hızına etkisinin belirlenmesi \\
Kimyasal kinetik & Katalizörün tepkime hızına etki etkisinin belirlenmesi \\
Kimyasal denge & Sıcaklık ve derişimin denge tepkimelerine etkisinin belirlenmesi \\
Termokimya & Çözünme ve nötralleşme ısılarının belirlenmesi \\
Asitler ve bazlar & Titrasyon yardımıyla asitlik derecesinin hesaplanması \\
Asitler ve bazlar & Tamponların çalışma mekanizmasının anlaşılması \\
Elektrokimya & Pil gerilimine derişimin etkisinin belirlenmesi \\
Elektrokimya & Pas giderme ve korozyonu engelleme yollarının belirlenmesi \\
\hline
\end{tabular}

Deney grubunda yer alan öğretmen adayları bir dönem süresince sanal laboratuvar ortamında sorgulamaya dayalı laboratuvar etkinliklerini yürütmüşlerdir. Kontrol grubunda bulunan öğretmen adayları ise yine sanal laboratuvar ortamında aynı etkinlikleri geleneksel yaklaşıma dayalı olarak gerçekleştirmişlerdir. Uygulamalar sonrasında her iki gruptaki öğretmen adayları, sınıf ortamı dışında dış etkenleri yok edecek özellikte düzenlenmiş kayıt odasına alınarak bireysel olarak EEG kayıtları alınmıştır. Bu süreçte, öğretmen adaylarından problem durumu sunulmuş ve hipotez kurmaları istenmiş ve EEG ölçümleri alınmıştır. Ayrıca öğretimsel işlemler sonunda her iki grupta yer alan öğretmen adaylarına Sorgulama Becerileri Ölçeği ve Bilimsel Süreç Becerileri Testi uygulanmış, ardından öğretmen adaylarıyla yarı yapılandırılmış görüşmeler gerçekleştirilmiştir.

\section{Deney grubunda yapılan uygulamalar}

Çalışma kapsamında deney grubunda sanal laboratuvar ortamında sorgulamaya dayalı laboratuvar etkinlikleri gerçekleştirilmiştir. Bu amaçla Mutlu (2015) tarafından geliştirilen sorgulamaya dayalı sanal kimya laboratuvarı (SDSKL) yazııımı kullanılmıştır.

Etkinliklere başlamadan önce öğretmen adaylarına gerek sorgulamaya dayalı öğrenme gerekse sanal laboratuvar kullanımı hakkında oryantasyon yapılmıştır. Ardından her bir sorgulamaya dayalı sanal laboratuvar etkinliği Genel Kimya II dersine paralel ilerleyecek şekilde uygulanmıştır. SDSKL yazılımında yer alan deneysel etkinlikler Hofstein, Shore ve Kipnis (2004) tarafından belirtilen sorgulamaya dayalı deney aşamalarını içerir şekilde geliştirilmiş olup bu aşamalara dayalı olarak etkinlikler gerçekleştirilmiştir. Bu bağlamda ilk olarak öğretmen adaylarına problem durumu içeren bir metin sunulmuş ve metinde yer alan problemi tanımlamaları istenmiştir. Ardından sırasıyla hipotez oluşturma, deney tasarlama, tasarlanan deneyi gerçekleştirme, verileri kaydetme, sonuçlara ulaşma ve yorumlama aşamaları gerçekleştirilmiştir. Her aşama ilgili yazııım vasıtasıyla öğretim üyesinin onayına sunulmuş, öğretim üyesinin onayı ile bir sonraki aşamaya geçiş yapılabilmiştir.

\section{Kontrol grubunda yapılan uygulamalar}

Sunulan çalışmada kontrol grubunda sanal laboratuvar ortamında geleneksel öğretmen merkezli yaklaşıma dayalı laboratuvar etkinlikleri gerçekleştirilmiştir. Bu amaçla Mutlu (2015) tarafından geliştirilen geleneksel sanal kimya laboratuvarı (GSKL) yazııımı kullanılmıştır.

Etkinliklere başlamadan önce öğretmen adaylarına gerek geleneksel öğretmen merkezli yaklaşım gerekse sanal laboratuvar kullanımı hakkında oryantasyon yapılmıştır. Ardından her bir sanal laboratuvar etkinliği Genel Kimya II dersine paralel ilerleyecek şekilde uygulanmıştır. GSKL yazılımında, SDSKL yazılımında yer alan deneysel etkinlikler 
geleneksel öğretmen merkezli yaklaşıma dayalı olarak tasarlanmış ve gerçekleştirilmiştir. Dolayısıyla GSKL yazılımında yalnızca deney yapılmıştır. Ayrıca yazılımda geleneksel öğretmen merkezli yaklaşıma uygun olacak şekilde deneyin adı, amacı, kullanılacak araç-gereçler ve deneyin yapılışı aşamalarını içeren deney yönergesi öğretmen adaylarının kullanımına hazır hale getirilmiştir. Yazılımda öğretmen adayları deneye ait sekmeyi tıkladığında doğrudan deney masası ile karşılaşmıştır. Ardından deney masasının sağ üst köşesinde yer alan yönerge sekmesini tıklayarak yönergede yer alan adımları takip ederek deneyi tamamlamışlardır.

\section{Verilerin Analizi}

Grupların uygulamaların sonrasında uygulanan Sorgulama Becerileri Ölçeği ve Bilimsel Süreç Becerileri Testi'nden elde ettiği puanların karşılaştırılmasında Mann Whitney-U testi kullanılmıştır. Mann Whitney-U testi sonuçlarının etki büyüklüğü ise $\mathrm{N}=1$. gruptaki kişi sayısı +2 . gruptaki kişi sayısı olmak üzere $r=z \sqrt{\mathrm{N}}$ formulü ile hesaplanmıştır (Pallant, 2007).

EEG verilerinin analizi, Actichamp Sistemle Uyumlu Brainvision EEG Analiz Yazılımı ile gerçekleştirilmiştir.

Çalışmanın yarı yapılandırılmış görüşmelerden elde edilen nitel verilerinin analizinde ise içerik analizi kullanılmıştır. Bu amaçla veriler kodlanmış, kodlara ilişkin temalar belirlenmiş ve her bir koda ait frekans değerleri hesaplanmıştır (Yıldırım ve Şimşek, 2013).

\section{Bulgular}

\section{Bilimsel Süreç Becerilerine İlişkin Bulgular}

Deney ve Kontrol gruplarındaki öğretmen adaylarının bilimsel süreç becerilerini belirlemek amacıyla, uygulamalardan sonra Bilimsel Süreç Becerileri Testi (BSBT) uygulanmıştır. Grupların BSBT'den elde ettikleri puanlara ilişkin tanımlayıcı istatistik sonuçları Tablo 2 'de sunulmuştur.

Tablo 2. Grupların BSBT'den elde ettikleri puanlara İlişkin Tanımlayıcı İstatistik Sonuçları

\begin{tabular}{llllll}
\hline Grup & $\mathrm{N}$ & Ortalama & Standart Sapma & En Düşük Puan & En Yüksek Puan \\
\hline Deney & 10 & 28.90 & 2.02 & 26.00 & 32.00 \\
Kontrol & 10 & 24.10 & 3.45 & 18.00 & 28.00 \\
\hline
\end{tabular}

Grupların BSBT'den elde ettikleri ortalama puanlara ilişkin sütun grafiği Grafik 1'de sunulmuştur.

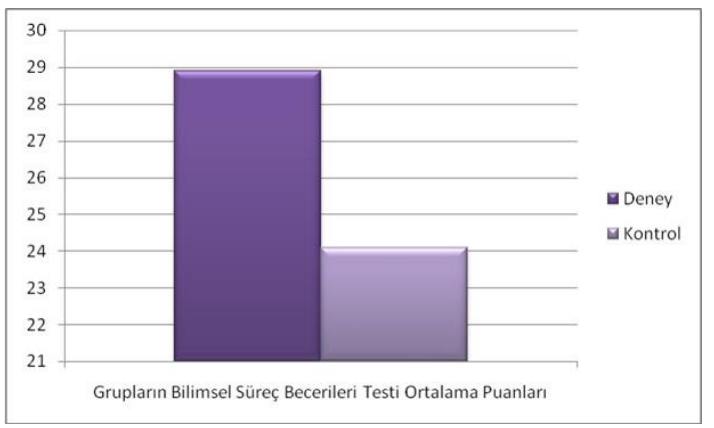

\section{Grafik 1. Grupların BSBT'den elde ettikleri ortalama puanlar}

Tablo 2 ve Grafik 1' de görüldüğü üzere, BSBT ortalama puanları Deney grubunda 28.90, Kontrol grubunda ise 24.10 olarak belirlenmiştir. Deney ve kontrol grubu öğretmen adaylarının BSBT ortalama puanları arasında istatistiksel olarak anlamlı bir farkın olup olmadığını belirlemek amacıyla Mann Whitney U testi işe koşulmuştur (Tablo 3). 
Tablo 3: Grupların BSBT'ne illişkin Mann Whitney U Testi Sonuçları

\begin{tabular}{llllll}
\hline Grup & N & Sıra Ortalamaları & Sıra Toplamları & U & $\mathrm{p}$ \\
\hline Deney & 10 & 14.55 & 145.50 & 9.500 & 0.002 \\
Kontrol & 10 & 6.45 & 64.50 & & \\
\hline
\end{tabular}

Analizler sonucunda, Deney ve Kontrol grupları ( $U=9.500, z=-3.077, p<0.05, r=0.69$ ) ortalama puanları arasında istatistiksel olarak anlamlı bir farklılık olduğu saptanmıştır.

\section{Sorgulama Becerilerine illişkin Bulgular}

Deney ve Kontrol gruplarındaki öğretmen adaylarının sorgulama becerilerini belirlemek amacıyla, uygulamalardan sonra Sorgulama Becerileri Ölçeği (SBÖ) uygulanmıştır. Grupların SBÖ’den elde ettikleri puanlara ilişkin tanımlayıcı istatistik sonuçları Tablo 4 'de sunulmuştur.

Tablo 4: Grupların SBÖ’den elde ettikleri puanlara iliş̧kin Tanımlayıcı İstatistik Sonuçları

\begin{tabular}{llllll}
\hline Grup & $\mathrm{N}$ & Ortalama & Standart Sapma & En Düşük Puan & En Yüksek Puan \\
\hline Deney & 10 & 60.20 & 5.81 & 53.00 & 66.00 \\
Kontrol & 10 & 50.90 & 6.69 & 43.00 & 62.00 \\
\hline
\end{tabular}

Grupların SBÖden elde ettikleri ortalama puanlara ilişkin sütun grafiği Grafik 3-2'de sunulmuştur.

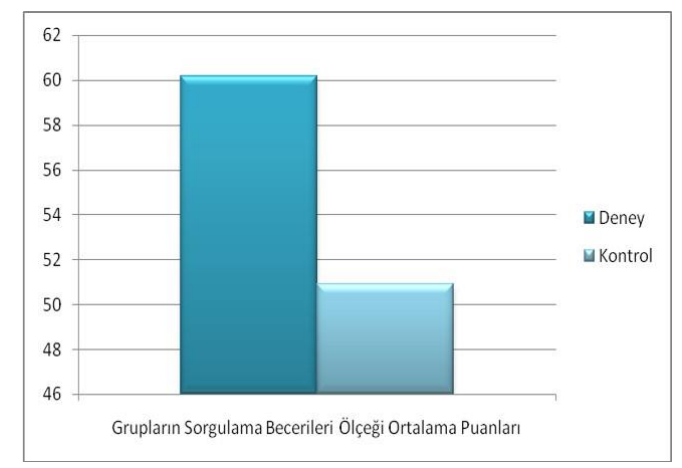

\section{Grafik 2. Grupların SBÖ’den elde ettikleri ortalama puanlar}

Tablo 4 ve Grafik 2' de görüldüğü üzere, SBÖ ortalama puanları Deney grubunda 60.20, Kontrol grubunda ise 50.90 olarak belirlenmiştir. Deney ve kontrol grubu öğretmen adaylarının SBÖ ortalama puanları arasında istatistiksel olarak anlamlı bir farkın olup olmadığını belirlemek amacıyla Mann Whitney U testi işe koşulmuştur (Tablo 5).

Tablo 5. Grupların SBÖ'ne Illişkin Mann Whitney U Testi Sonuçları

\begin{tabular}{llllll}
\hline Grup & $\mathrm{N}$ & Sıra Ortalamaları & Sıra Toplamları & $\mathrm{U}$ & $\mathrm{P}$ \\
\hline Deney & 10 & 14.00 & 145.50 & 15.000 & 0.008 \\
Kontrol & 10 & 7.00 & 70.00 & & \\
\hline
\end{tabular}

Analizler sonucunda, Deney ve Kontrol grupları $(U=15.000, z=-2.655, p<0.05, r=0.59)$ ortalama puanları arasında istatistiksel olarak anlamlı bir farklılık olduğu saptanmıştır.

\section{EEG Ölçümlerine ilişskin Bulgular}

Çalışma kapsamında, Deney grubu ve Kontrol grubunda yer alan 20 öğretmen adayının EEG kayıtları alınmıştır. EEG kayıtları uluslararası 10-20 sistemine göre hazırlanmış bir başlıkla başa oturtulan 64 aktif elektrot yardımıyla 500 $\mathrm{Hz}$ örnekleme sıklığında alınmıştır. Katıımcıların dinlenme ve hipotez kurma sürecinde EEG kayıtları alınmıştır. Veriler, standart Fast Fourier Transform (FFT) yöntemiyle analiz edilip her bir frekansın spektral gücü hesaplanmıştır. Sonuçlar, 
katılımcıların hipotez geliştirirken frontal teta frekansı gücünün belirgin derecede artmış olduğunu göstermiştir. Buna göre, frontal teta spektral gücünün öğrenmenin bir indikatörü olarak gösterilebileceği düşünülmüştür. Deney ve kontrol grubundaki katılımcıların hipotez geliştirirken sağlanan frontal teta frekansı gücü kıyasladığında ise her gruptaki katılımcıların frontal teta frekansı gücünün değişiminin benzer olduğu ve iki grup arasında fark olmadığı belirlenmiştir.

\section{Yarı Yapılandırılmış Görüşmelere illişkin Bulgular}

Deney ve kontrol grubundaki öğretmen adaylarının yürütülen uygulama hakkındaki görüşlerini belirlemek amacıyla uygulama sonrasında tüm öğretmen adayları ile yarı yapılandırılmış görüşmeler yapılmış ve öğretmen adaylarının yanıtlarına yönelik içerik analizi gerçekleştirilmiştir. Öğretmen adaylarının yanıtlarına ait içerik analizi ve frekans değerleri Tablo 6'da sunulmuştur.

Tablo 6. Grupların Yarı Yapılandırılmış Görüşmelerdeki Yanıtlarının İçerik Analizi ve Frekansları

\begin{tabular}{|c|c|c|c|}
\hline Temalar & Kodlar & $\begin{array}{l}\text { Deney } \\
\text { (f) }\end{array}$ & $\begin{array}{l}\text { Kontrol } \\
\text { (f) }\end{array}$ \\
\hline Kendi & illginçti & 10 & - \\
\hline deneyini & Öğreticiydi & 8 & - \\
\hline \multirow[t]{3}{*}{ tasarlama } & Düşündürücüydü & 10 & - \\
\hline & Durumu sorgulatıcıydı & 4 & - \\
\hline & Beceri geliştiriciydi & 5 & - \\
\hline Çalışmada en & Problem oluşturma & - & - \\
\hline beğenilen & Hipotez kurma & 2 & - \\
\hline \multirow[t]{3}{*}{ kısım } & Deney tasarlama & 3 & - \\
\hline & Deneyi uygulama & 5 & - \\
\hline & Deney sonuçlarını yorumlama & - & - \\
\hline Çalışmada en & Problem oluşturma & 2 & - \\
\hline zorlanılan & Hipotez kurma & 2 & - \\
\hline \multirow[t]{3}{*}{ kısım } & Deney tasarlama & 4 & - \\
\hline & Deneyi uygulama & - & - \\
\hline & Deney sonuçlarını yorumlama & 2 & - \\
\hline Çalışmanın & Hipotez kurma becerisi geliştirici & 10 & - \\
\hline \multirow[t]{10}{*}{ katkısı } & Dönütlerin geliştirici olması & 10 & - \\
\hline & Daha derinlemesine düşünmeyi sağlayıcı & 10 & 3 \\
\hline & Özgüven arttırıcı & 10 & 2 \\
\hline & Mantık yürütücü & 10 & - \\
\hline & Daha az düşündürücü & - & 5 \\
\hline & Düşünmeden, sadece yönergeyi takip etme & - & 10 \\
\hline & Bilgisayar ortamında zamandan tasarruf & 5 & 10 \\
\hline & Bilgisayar ortamının kimyasal korkusunu azaltması & 8 & 8 \\
\hline & Bilgisayarda deneyin ilginç bir tecrübe olması & 10 & 10 \\
\hline & EEG kayıtlarının farklı bir tecrübe oluşu & 10 & 10 \\
\hline
\end{tabular}

Yapılan içerik analizi neticesinde, yirmi altı kod belirlenmiş ve bu kodlar kendi deneyini tasarlama, çalışmada en beğenilen kısım, çalışmada en zorlanılan kııım ve çalışmanın katkısı olmak üzere dört temada toplanmıştır. Öğretmen adaylarının yanıtları incelendiğinde, Deney grubundaki öğretmen adayları, genel olarak olumlu düşünceler belirttiği tespit edilmiştir. Kontrol grubundaki öğretmen adayları ise bilgisayar ortamında deney yapmanın ilginç olmasının yanı sıra yönergeyi takip ederek deneyi yaptıklarını ve daha az düşündüklerini bildirmiştir.

\section{Sonuçlar}

Sunulan araştırmada, bilgisayar ortamında sorgulamaya ve geleneksel öğrenme yaklaşımlarına dayalı deneysel etkinlikler gerçekleştiren Fen Bilgisi öğretmen adaylarının beyin fonksiyonlarındaki değişimin EEG ile belirlenmesi ve verilerin sorgulama ve bilimsel süreç becerileri ile ilişkilendirilmesi amaçlanmıştır. Bu amaçla Fen öğretmen adaylarına 
bilimsel süreç becerileri testi ve sorgulama becerileri ölçeği uygulanmış, yarı yapılandııılmış görüşmeler yapılmış ve EEG ölçümleri alınmıştır.

Analiz sonuçlarına göre, sorgulamaya dayalı sanal laboratuvar etkinliklerinin yapıldığı deney grubu ve geleneksel yaklaşıma dayalı sanal laboratuvar etkinliklerinin yapıldığı kontrol grubunun bilimsel süreç becerileri testinden elde ettikleri puanlar arasında anlamlı bir farklılık olduğu, sıra ortalamaları göz önüne alındığında bu farkın deney grubu lehine olduğu saptanmıştır. Yarı yapılandırımış görüşme sonuçları göz önüne alındığında kontrol grubuna kıyasla deney grubunda daha fazla sayıda öğretmen adayı uygulamaların becerilerini geliştirdiğini, hipotez kurma becerilerinin geliştiğini, daha derinlemesine düşünmeyi sağladığını belirtmiştir. Alan yazında da belirtildiği gibi sorgulamaya dayalı öğrenmenin dayanak noktalarından biri bilimsel süreç becerileridir. Eğitimin farklı kademelerinde yürütülen çalışmalar, çalışmamızın bulgularına paralel olarak, sorgulamaya dayalı öğrenmenin ilkokul-ortaokul (Ergül vd., 2011; Kaya ve Yılmaz, 2016; Yıldırım, 2017), lise (Khan ve Iqbal, 2011) ve yükseköğrenim (Şensoy ve Yıldırım, 2017; Yıldırım, Kurt ve Güneş, 2014) düzeyinde geleneksel yaklaşıma kıyasla bilimsel süreç becerilerini geliştirmede daha etkili olduğu ortaya konmuştur.

Çalışma kapsamında öğretmen adaylarının sorgulama becerileri kıyaslanmış, deney ve kontrol gruplarının sorgulama becerileri ölçeğinden elde ettikleri puanlar arasında anlamlı bir farklılık olduğu ve sıra ortalamaları göz önüne alındığında bu farkın deney grubu lehine olduğu saptanmıştır. Yarı yapılandırılmış görüşme sonuçları göz önüne alındığında kontrol grubuna kıyasla deney grubunda daha fazla sayıda öğretmen adayı uygulamaların durumları sorgulatıcı, dönütlerin geliştirici olduğunu ve beceri geliştirici olduğunu belirtmiştir. Elde edilen sonuçlar sorgulamaya dayalı etkinliklerin sorgulama becerilerine etkisinin araştııılı̆̆ı alan yazınla uyumludur (Hairida, 2016; Wu ve Hsieh 2006).

Sunulan çalışmada bir dönem süresince sorgulamaya dayalı ve geleneksel yaklaşıma dayalı sanal laboratuvar etkinlikleri gerçekleştiren fen öğretmen adaylarının uygulamalar sonunda sunulan problem durumuna yönelik hipotez kurma aşamalarında EEG kayıtları alınmıştır. Bulgular katııımcıların hipotez geliştirirken frontal teta frekansı gücünün belirgin derecede artmış olduğunu göstermiştir. Alan yazında öğrenme indikatörü olarak EEG ölçümlerinin kullanıldığı çalışmalar bulunmakta olup, çalışmamızın amacı ve bulguları ile uyum göstermektedir (Fink vd. 2009; Jausiovec, 2000; Jin vd., 2006; Rashid vd., 2012; Stevens, Galloway ve Berka 2006).

Deney ve kontrol grubundaki katılımcıların hipotez geliştirirken sağlanan frontal teta frekansı gücü kıyasladığında ise her gruptaki katılımcıların frontal teta frekansı gücünün değişiminin benzer olduğu ve iki grup arasında fark olmadığı belirlenmiştir. Bu durum bireylerin hipotez kurarken beyninin aynı lobunu ve benzer alanı kullandığını ve buna bağıı olarak beyinsel fonksiyonlar bakımından benzer frekans gücü değişimi gösterdiklerini ortaya koymuştur. Bu durum her iki grubun hipotez kurma sürecinde beyninin belli bir bölgesinin aktif olduğu ve benzer refleksi verdiğini; beynin kullanımının kullanılan öğretim yaklaşımına bağlı olmadığı şeklinde yorumlanmaktadır. Bununla birlikte sorgulamaya dayalı ortamda çalışan öğrencilerin daha yüksek bilimsel süreç ve sorgulama becerilerine sahip olduğu görülmektedir. Bu bulgu ise geleneksel öğrenme yaklaşımı ile çalışan öğretmen adaylarının sorgulamaya dayalı ortamda çalışması ile anılan becerilerinin gelişeceği yönünde yorumlanmıştır.

\section{5. Öneriler}

Nobel ödüllü bilim insanımız sayın Prof. Dr. Aziz Sancar'ın da belirttiği gibi çoğu insanı birbirinden ayıran zekâdan ziyade harcanan emektir. Çalışmamızın bulgularında da görüldüğü üzere aynı bilişsel işlemi gerçekleştiren öğretmen adaylarının beyin refleksleri aynı iken, sorgulamaya dayalı öğrenme ortamında daha aktif çalışan öğretmen adaylarının becerilerinin daha yüksek olduğu görülmektedir. Öğretmen eğitimi geleceğe yapılacak en önemli yatırımdır. Çünkü bir öğretmenin çeşitli becerilere sahip olması onu gelecekteki sınıfında kullanabilmesi ve öğrencilerinde de bu becerileri geliştirebilmesi anlamına gelir. Bu sebeple öğretmen adaylarının çeşitli becerilerini geliştirebileceği öğrenme ortamlarında yer almaları gerekmektedir. Çalışmanın bulguları ısığında öğrenme ortamlarının öğretmen adaylarını daha aktif kılacak sorgulamaya dayalı öğrenme gibi yaklaşımların temel alınarak düzenlenmesi önerilmektedir. 


\section{Teşekkür}

Bu çalışma İstanbul Üniversitesi-Cerrahpaşa Bilimsel Araştırma Projeleri Koordinasyon Birimi tarafından desteklenmiştir. Proje numarası: 50694

\section{Kaynakça}

Aldan-Karademir, Ç., \& Saracaloğlu, A. S. (2013). Sorgulama becerileri ölçeği'nin geliştirilmesi: geçerlik ve güvenirlik çalışması. Asian Journal of Instruction, 1(2), 56-65.

Ateş, S., \& Bahar, M. (2002). Developing scientific process skills of prospective elementary teachers by using investigative teaching approach of science. V. National Science and Mathematics Education Congress, Ankara.

Burns, J. C., Okey, J. C. \& Wise, K. (1985). Development of an integrated process skills test:TIPS II. Journal of Research in Science Teaching, 22(2), 169-177.

Chiappetta, E. L., \& Adams, A. D. (2004). Inquiry-based instruction. The Science Teacher, 71(2), 46-50.

Ergül, R., Şimşekli, Y., Çalış, S., Özdilek, Z., Göçmençelebi, Ş., \& Şanlı, M. (2011). The effects of inquıry-based science teaching on elementary school students' science process skills and science atitudes. Bulgarian Journal of Science \& Education Policy, 5(1), 48-68.

Fink, A., Grabner, R. H., Benedek, M., Reishofer, G., Hauswirth, V., Fally, M., Neuper, C., Ebner, F., \& Neubauer, A. C. (2009). The creative brain: Investigation of brain activity during creative problem solving by means of EEG and FMRI, Human Brain Mapping 30, 734-748.

Hairida, H. (2016). The effectiveness using inquiry based natural science module with authentic assessment to improve the critical thinking and inquiry skills of junior high school students. Jurnal Pendidikan IPA Indonesia, 5(2), 209215.

Hofstein, A., Shore, R. \& Kipnis, M. (2004). Providing high school chemistry students with opportunities to develop learning skills in an inquiry-type laboratory: a case study. International Journal of Science Education, 26(1), 4762.

Jausovec, N. (2000). Differences in cognitive processes between gifted, intelligent, creative, and average individuals while solving complex problems: an EEG study. Intelligence, 28(3), 213- 237.

Jausovec, N., \& Jausovec, K. (2000). EEG activity during the performance of complex mental problems. International Journal of Psychophysiology, 36, 73-88.

Jin, S. H., Kwon, Y. J., Jeong, J. S., Kwon, S. W., \& Sjin, D. H.(2006). Increased information transmission during scientific hypothesis generation: Mutual information analysis of multichannel EEG. International Journal of Psychophysiology, 62, 37-344.

Kaya, G., \& Yılmaz, S. (2016). Açık sorgulamaya dayalı öğrenmenin öğrencilerin başarısına ve bilimsel süreç becerilerinin gelişimine etkisi. Hacettepe Üniversitesi Eğitim Fakültesi Dergisi, 31(2), 300-318.

Khan, M., \& Iqbal, M. Z. (2011). Effect of inquiry lab teaching method on the development of scientific skills through the teaching of biology in Pakistan. Language in India, 11(1), 169-178.

Milli Eğitim Bakanlı̆̆ı (2018). Fen Bilimleri Dersi Öğretim Programı (ilkokul ve Ortaokul 3, 4, 5, 6, 7 ve 8. sınıflar). Ankara: Talim Terbiye Kurulu Başkanlığı.

Mölle, M., Marshall, L., Gais, S., \& Born, J. (2004). Learning increases human electroencephalographic coherence during subsequent slow sleep oscillations. Proceedings of the National Academy of Sciences, 101(38), 1396313968. 
Mutlu, A. (2015). Genel kimya düzeyinde gerçek ve sanal laboratuvar ortamlarında gerçekleştirilen rehberli sorgulamaya dayalı etkinliklerin öğrenme sürecine etkisi (Yayımlanmamış doktora tezi). İstanbul Üniversitesi, Eğitim Bilimleri Enstitüsü, Fen Bilgisi Eğitimi Anabilim Dalı, İstanbul

National Research Council (NRC). (2000). Inquiry and national science educational standards. Washington DC.: National Academy Press.

Pallant, J. (2007). SPSS Survival manual, a step by step a guide to data analysis using SPSS for Windows. England: McGraw-Hill Education.

Pehlivan, F. (1997). Biyofizik. Ankara: Hacettepe-Taş Kitapçılık.

Rashid, N. A., Taib, M. N., Lias, S., Sulaiman, N., Murat, Z. H., \& Kadir, R. S. S. A. (2012). Learners' Learning Style correlated to Agreeableness based on EEG. In The 2012 International Conference on Management and Education Innovation..

Schwab, J. J. (1962). The teaching of science as Inquiry. In J.J. Schwab and P.F.Brandwein (Eds) The Teaching of Science. Cambridge: Harvard University Pres.

Stevens, R., Galloway, T., \& Berka, C. (2006). Integrating EEG Models of Cognitive Load with Machine Learning Models of Scientific Problem Solving. In D. Schmorrow, K. Stanney \& L. Reeves (Eds.), Augmented Cognition: Past, Present and Future (2 ed., pp. 55-65), Arlington, VA: Strategic Analysis, Inc.

Summerfield, C., \& Mangels, J. A. (2004). Coherent theta-band EEG activity predicts item-context binding during encoding. Neurolmage, 24, 692-703.

Şensoy, Ö., \& Yıldırım, H. İ. (2017). Araştırma soruşturma tabanlı öğrenme yaklaşımının yaratıcı düşünme ve bilimsel süreç becerilerine etkisi. Cumhuriyet Uluslararası Eğitim Dergisi, 6(1), 34-46.

Wu, H. K., \& Hsieh, C. E. (2006). Developing sixth graders' inquiry skills to construct explanations in inquiry-based learning environments. International Journal of Science Education, 28(11), 1289-1313.

Yıldırım, N., Kurt, S., \& Güneş, L. (2014). Effects of inquiry based learning activities on scientific process skills and academic achievement of preservice classroom teachers. International Journal of Academic Research, 6(6), 4654.

Yıldırım, A. \& Şimşek, H. (2013). Sosyal bilimlerde nitel araştırma yöntemleri. Ankara: Seçkin Yayıncılık.

Yıldııım, M., \& Türker-Altan, S. (2017). Araştırma ve sorgulamaya dayalı öğrenme yaklaşımının ilkokul öğrencilerinin bilimsel süreç becerilerine etkisi. Mustafa Kemal Üniversitesi Sosyal Bilimler Enstitüsü Dergisi, 14(38), 71-89. 